\title{
DESIGN OF COMPELEMENTARY RING ARRAY ANTENNA
}

\author{
Dr. Eanass U. T. Al-Shabkhoon \\ Dept. of Med. Instrumentation Eng. \\ Technical College / Mosul / Iraq \\ Foundation of Technical Learning
}

\begin{abstract}
The objective of work is to find the scale of ring array antenna for localizing field intensity at certain focal point. The study is interested in comparison between focusing by setting a scale factor of array antenna to cohere (synchronize) waves of electric field when reaching focal point, and focusing by compensating phase differences that was initiated from ray length differences between waves reaching focal point. Isotropic sources are used for simulation. These sources are distributed along a circular ring, each ring of array rings is complement with the previous rings, that means it has a phase complement to a complete cycle ( ).
\end{abstract}

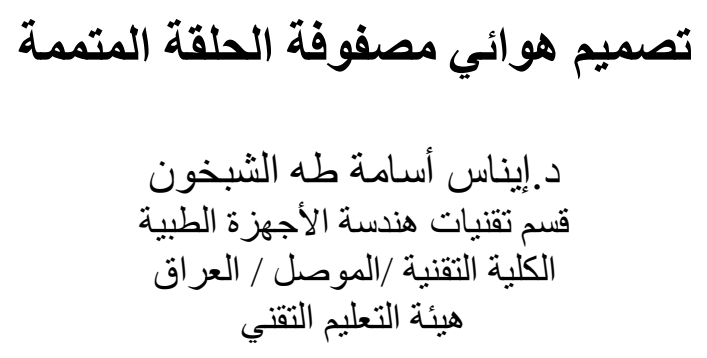

الملخص

تم العمل في البحث الحالي على إيجاد أبعاد هو ائي المصفوفة الحلقي لغرض تركيز الأشعة عند نقطة محددة, حيث أن إهنمام الدراسة ينصب على المقارنة بين التركيز عن طريق و ضع ضع أبعاد محددة لمصفوفة

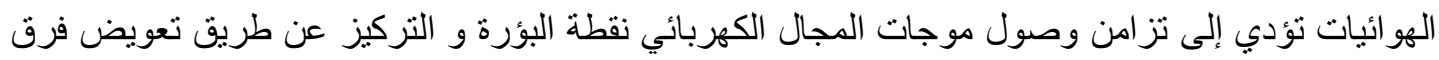

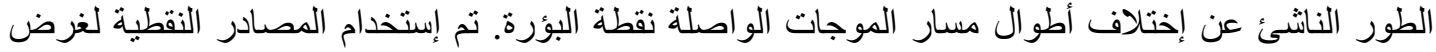
النمـذجة. وزعت هذه المصادر على حلقات دائرية الثكل كل حلقة من حلقات المصفوفة النهة منممة لسابقتها من

حيث البعد أي أن لها فرق طور منمم لدورة كاملة ( ). 


\section{Introduction:}

Coherency, array antenna, focusing in near field, all these subjects were studied in the past year $[1,2,3]$. Ring is one of the important shape that is studied as a standard type of antenna. The central focal point of such antenna type can be displaced up or down much easier than planner antenna. The interest of localization field intensity in near field region is to have a high field intensity and a narrow beam distribution. S. Jacobsen [4] used ring antenna with spiral antenna at the same time for hyperthermia therapy.

This paper is interested in studying ring antenna as a focusing device without need for excitation function (current excitation of array elements is uniform). The condition of focusing can be verified by compensating the ray length of propagation waves to reach focal point coherently (without phase differences). The configuration of antenna array is shown in figure (1).

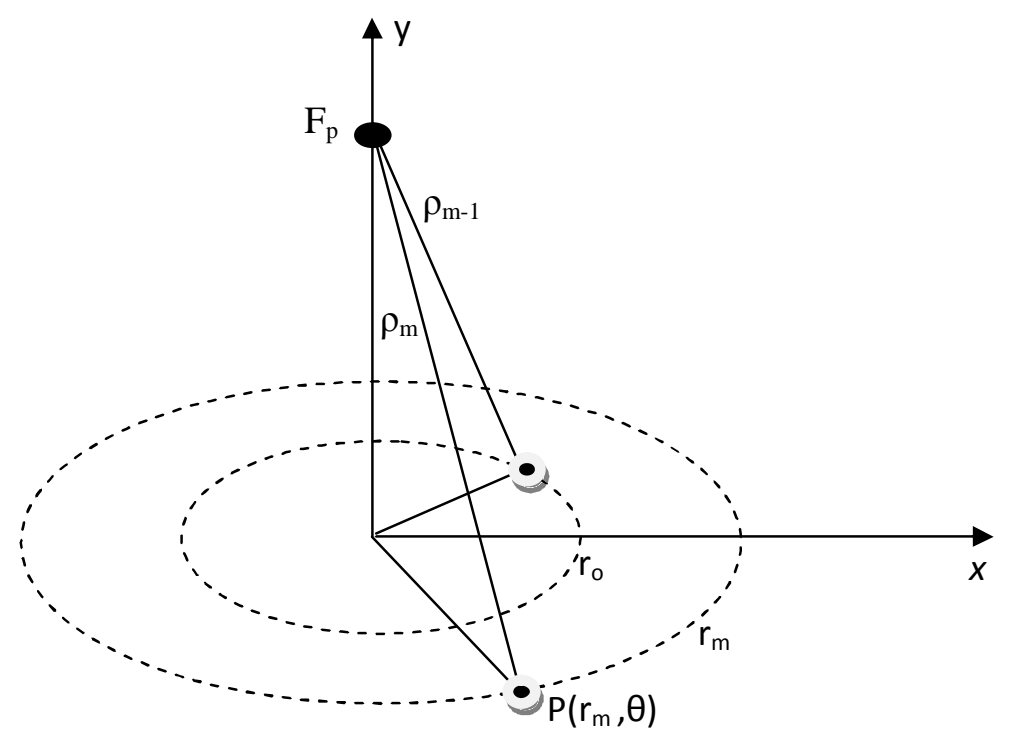

Figure (1): The Structure of Ring Array Antenna

Antenna elements is located at position $\mathrm{P}\left(\mathrm{r}_{\mathrm{m}}, \theta_{\mathrm{m}}\right)$. Elements of antenna within a certain ring array have a uniform distance from focal point, which means that all elements have an equi-phase shift, an equi-ray length, and an equi-electric length. Distance from antenna can be divided into first order, second order, third order, and ...etc. orders according to the series expansion as a result phase of array is divided 
into linear, quadratic, cubic, and so on, return to Stenberig [1] for more details about series.

The radius of rings $m$ can be set according to:

$r_{m}^{2}=\rho_{m}^{2}-F_{p}^{2}$

The differences between ray lengths of two sequential rings (

is adjusted to $\lambda / 2$ by scaling up the radius of ring as a start point of design complementary ring array antenna, where:

$\rho_{m-1} \rho_{m-1}=\frac{\lambda}{2} \cdot(-1)^{m}$

The radius of ring is a result of adjusting and it can be calculated from equation below:

$\left.r_{m}^{2}\right|_{F_{p}=n \lambda}=r_{m-1}^{2}-2 n \lambda^{2}(-1)^{m}$

Where $\mathrm{n}$ is an arbitrary integer number.

Actually phase differences are cancelled at focal point $\mathbf{F}_{\mathbf{p}}$, since the electrical ray lengths of waves are identical. Phase conjugate method can be used to compensate the ray length differences, where the amount of additive phase constant is:

$\left.\beta_{m}\right|_{y=F_{p}}=2 \pi\left(\rho_{m}-F_{p}\right) / \lambda$

\section{Simulation and Results:}

A ring array antenna is simulated for: 
- Number of elements per ring $=4$ elements.

- Number of rings $=4$ rings.

- Focal point is located at $\mathrm{F}_{\mathrm{p}}(0,0,10 \lambda)$.

- Element location is selected according to equation (1).

Field distribution is estimated for the above case, as it can be seen in figure (2). Figure (3) is for uniform - focused - ring- phased- array - antenna, which has the same number of elements and rings.

\section{Conclusion:}

Focal point and its zooming are observed certainly as a red or 'dark' spot in figure (2) and figure (3) but the level of minor lobes in figure (2) are high as it can be seen by the color bar of contour plot. Differences between the two cases are inner dimension of rings and phase excitation.

Field intensity can be localized in near field region without scattering using uniform linear array antenna as it was proven in previous study [5], if focal distance with respect to antenna dimension, verify the following:

$F_{p} \geq \frac{L}{2 \sqrt{2}}$

Where $\mathrm{L}$ is the maximum length of antenna and it can be considered as the radious $\mathbf{r}$ here.

That means there is an upper and lower limit of focal point that may cause the appearance of high minor lobes level. The condition of upper focal point limit in equation (5) was discussed in the previous study [5], but some points of view about coherency and compensating can be added according to the recent situation.

Point of view: when the relation of is derived, the phase differences at focal point is cancelled (field intensity is localized at focal point); that is a true, but phase shift does not convert into a linear phase shift. Quadratic, cubic, and ...etc. terms of phase shift are still occurs at other points of focal plane as a result of series expansion (scattering or small minor lobes are observed). The benefit of phase conjugate 
method is the ability of compensating higher order phase shift at focal plane in addition to localizing field intensity.

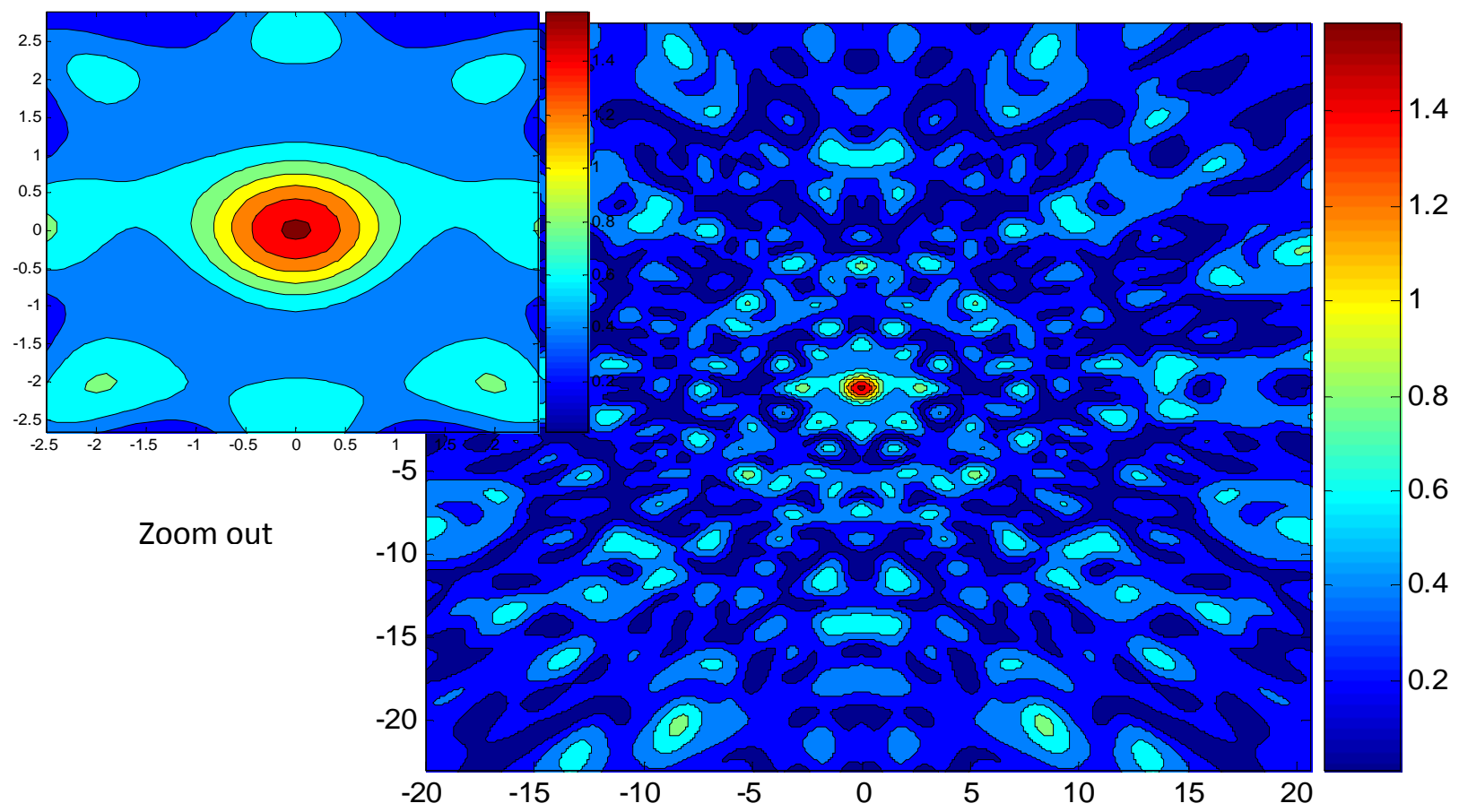

Figure (2): Field distribution of coherent ring array antenna

Note that scale of distance is in $[\mathrm{cm}]$ and the scale of intensity is in $[\mathrm{V} / \mathrm{cm}]$

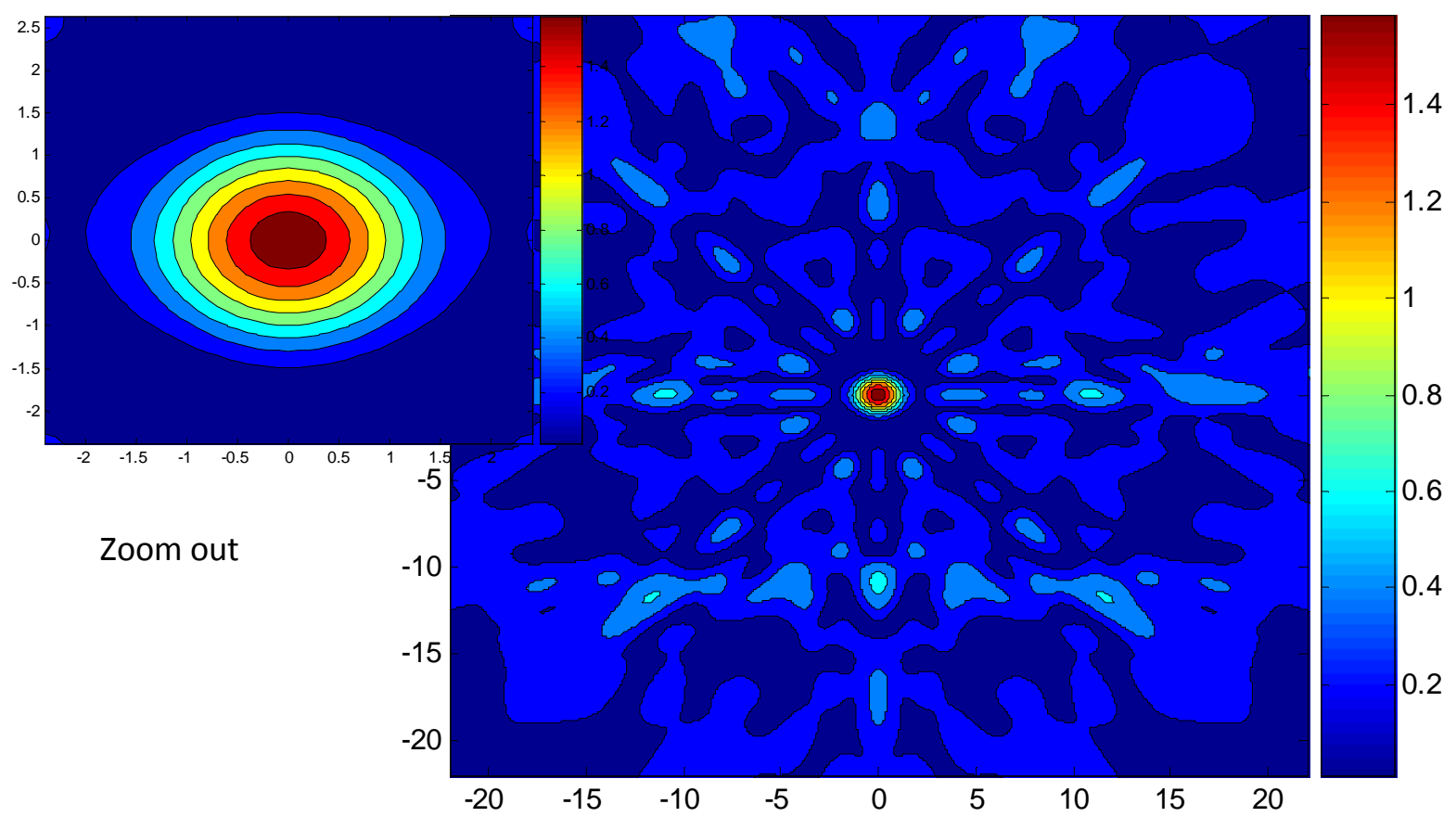


Figure (3): Field distribution of phased ring array antenna

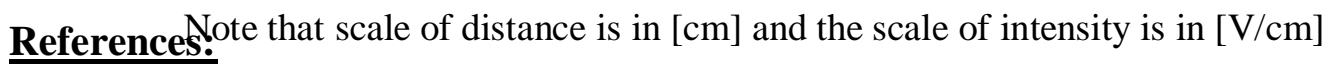

[1] B. D. Stenberig "Principle of Aperture and Array System Design", John Wiely and Sons, 1976.

[2] C. A. Balanis “Antenna Theory Analysis and Design”, Harper and Row, 1982.

[3] V. Gupta, S. Sinha, S. K. Koul, and B. Bhat "Wide Band Dielectric Resonator Loaded Suspended Microstrip Patch Antennas", Microwave AND Optical Technology Lelters Vol. 37, No. 4, 20 May 2003.

[4] S. Jacsobsen, "Dual Antenna Concept for Simultaneous Thermography and and Hyperthermic Heating', Electronic Letters, Vol. 34, No.1, 8 th January 1998.

[5] E. Shabkhoon "Focusing Feasibility in Fractal Array Antennas", Ph. D. Thesis, University of Mosul, 2006-2007. 